\title{
Article \\ Ultrasound-Based Molecular Imaging of Tumors with PTPmu Biomarker-Targeted Nanobubble Contrast Agents
}

\author{
Mette L. Johansen ${ }^{1}$, Reshani Perera ${ }^{2}$, Eric Abenojar ${ }^{2}{ }^{(}$, Xinning Wang ${ }^{3}$, Jason Vincent ${ }^{1}$, Agata A. Exner ${ }^{2,3, *(\mathbb{C}}$ \\ and Susann M. Brady-Kalnay ${ }^{1, *}$ (1) \\ 1 Department of Molecular Biology and Microbiology, School of Medicine, Case Western Reserve University, \\ 10900 Euclid Ave, Cleveland, OH 44106-4960, USA; mette.johansen@case.edu (M.L.J.); \\ jason.vincent@case.edu (J.V.) \\ 2 Department of Radiology, Case Western Reserve University, Cleveland, OH 44106-4960, USA; \\ reshani.perera@case.edu (R.P.); eric.abenojar@case.edu (E.A.) \\ 3 Department of Biomedical Engineering, Case Western Reserve University, Cleveland, OH 44106-7207, USA; \\ xinning.wang@case.edu \\ * Correspondence: agata.exner@case.edu (A.A.E.); susann.brady-kalnay@case.edu (S.M.B.-K.)
}

check for updates

Citation: Johansen, M.L.; Perera, R.; Abenojar, E.; Wang, X.; Vincent, J.; Exner, A.A.; Brady-Kalnay, S.M. Ultrasound-Based Molecular Imaging of Tumors with PTPmu Biomarker-Targeted Nanobubble Contrast Agents. Int. J. Mol. Sci. 2021, 22, 1983. https://doi.org/10.3390/ ijms22041983

Academic Editor: Uday Kishore

Received: 3 January 2021

Accepted: 11 February 2021

Published: 17 February 2021

Publisher's Note: MDPI stays neutral with regard to jurisdictional claims in published maps and institutional affiliations.

Copyright: (c) 2021 by the authors. Licensee MDPI, Basel, Switzerland. This article is an open access article distributed under the terms and conditions of the Creative Commons Attribution (CC BY) license (https:// creativecommons.org/licenses/by/ $4.0 /)$.

\begin{abstract}
Ultrasound imaging is a widely used, readily accessible and safe imaging modality. Molecularly-targeted microbubble- and nanobubble-based contrast agents used in conjunction with ultrasound imaging expand the utility of this modality by specifically targeting and detecting biomarkers associated with different pathologies including cancer. In this study, nanobubbles directed to a cancer biomarker derived from the Receptor Protein Tyrosine Phosphatase mu, PTPmu, were evaluated alongside non-targeted nanobubbles using contrast enhanced ultrasound both in vitro and in vivo in mice. In vitro resonant mass and clinical ultrasound measurements showed gas-core, lipid-shelled nanobubbles conjugated to either a PTPmu-directed peptide or a Scrambled control peptide were equivalent. Mice with heterotopic human tumors expressing the PTPmu-biomarker were injected with PTPmu-targeted or control nanobubbles and dynamic contrast-enhanced ultrasound was performed. Tumor enhancement was more rapid and greater with PTPmu-targeted nanobubbles compared to the non-targeted control nanobubbles. Peak tumor enhancement by the PTPmu-targeted nanobubbles occurred within five minutes of contrast injection and was more than $35 \%$ higher than the Scrambled nanobubble signal for the subsequent two minutes. At later time points, the signal in tumors remained higher with PTPmu-targeted nanobubbles demonstrating that PTPmu-targeted nanobubbles recognize tumors using molecular ultrasound imaging and may be useful for diagnostic and therapeutic purposes.
\end{abstract}

Keywords: nanobubbles; PTPmu; receptor protein tyrosine phosphatase; molecular imaging; dynamic contrast enhanced ultrasound; ultrasound contrast agents; time intensity curve

\section{Introduction}

The use of ultrasound (US) imaging for diagnostic purposes has grown considerably in recent years due to its wide availability, its adaptability, its safety profile and high sensitivity [1,2]. Recent data show that the annual number of ultrasound imaging procedures was second only to diagnostic X-rays and far surpassed the number of computed tomography (CT) scans, which was the third most common diagnostic imaging modality [1]. Advantages of US relative to X-ray, CT, and positron emission tomography (PET) scans include the absence of patient exposure to any ionizing radiation and the real time conveyance of information to clinicians $[1,3,4]$. Compared to magnetic resonance imaging (MRI) and CT/PET scanners, US instruments are less expensive and more portable, qualities that contribute to cost-effective diagnostic applications with equivalent or improved accuracy in many applications [5]. 
Ultrasound contrast agents (UCAs) are used to enhance US imaging and can be adapted for therapeutic and theranostic uses [2-4,6-8]. Currently, commercially available UCAs are categorized as microbubbles (MBs) with sizes ranging from 1 to $10 \mu \mathrm{m}$ and consist of phospholipid or albumin shells that enclose an echogenic perfluorocarbon gas $[2-4,6,8,9]$. MBs act as blood pool contrast agents since their size prevents their transit out of the blood stream [2-4,6,8,9]. Relative to contrast agents used in MRI and PET/CT which may be nephrotoxic, hepatotoxic, and/or radioactive, UCAs are considered very safe $[1,3,6]$. UCAs have been used worldwide in clinical applications for over 20 years, although the number and types of approved applications differ by country $[4,6]$. In the United States, FDA-approved MBs for echocardiography have been available since the 1990s and are used primarily to improve delineation of the left ventricular endocardial border, which is achieved by enhancing or "opacifying" the blood within it in a procedure termed "left ventricle opacification (LVO)" $[1,4,6,10]$. The ability to monitor blood flow in real-time also makes it possible for clinicians to use these UCAs in assessing myocardial perfusion following suspected cardiac events $[1,4,6,10]$. More recently, approved applications in the United States include the use of UCAs to examine liver lesions and for voiding urosonography $[4,6]$, applications that underscore the advantages of being able to dynamically image fluid flow. In liver, contrast enhanced US (CEUS) can be used to distinguish between different types of malignant and benign lesions based on the patterns of phase enhancement (reviewed in $[4,6]$ ), and may provide a cost-effective alternative to the more standard use of MRI. MBs have also shown preclinical utility in imaging kidney lesions and in assessing perfusion in recently transplanted kidneys $[4,6]$.

Recent advances in UCA technology include the development of molecular UCAs, which are agents with targeting moieties that recognize and bind to molecules upregulated on specific tissues or cells during pathologic states such as cancer or inflammation (reviewed in $[2,7,8]$ ). Some examples include UCAs targeted to prostate specific membrane antigen (PSMA) for use in imaging prostate cancer [11,12], and BR55, a MB-based agent targeted to vascular endothelial growth factor receptor 2 (VEGFR2), a hallmark of tumor-associated angiogenesis $[13,14]$. Along with increasing specificity, investigations are also underway to adapt UCAs for therapeutic use [7,15-17]. Several strategies have been employed to take advantage of the unique attributes of US and UCAs for applications such as drug delivery, transient opening of the blood brain barrier and ablation [7,15-17]. In addition to these refinements in MB design, an active area of UCA research involves the development of nanobubbles (NBs) to complement the use of MBs and/or expand the potential for therapeutic and theranostic applications. NBs are particles $<1 \mu \mathrm{m}$ (generally $100-500 \mathrm{~nm}$ ) in diameter and have a structure similar to MBs, with a phospholipid or polymer shell with a hydrophobic gas core. In contrast to MBs, NBs are small enough to transit out of the blood stream $[2,3,8,12,15]$ thus making more tissues accessible to NB-based theranostics. As with MBs, targeting molecules conjugated to the NB surface further extend the utility of NBs by making them specific for tumors or other target cells and tissues. The objective of this study was to utilize a highly stable NB formulation $[11,18]$ with a new targeting strategy using a Receptor Protein Tyrosine Phosphatase mu (PTPmu/PTP $\mu)$ targeting peptide, SBK2. We evaluated the specificity of PTP $\mu$-targeted NBs compared to non-targeting NBs with a non-specific scrambled peptide in an in vivo tumor model.

РTP $\mu$ is a member of the receptor protein tyrosine phosphatase family and is important for mediating cell-cell adhesion via homophilic interactions. In healthy cells, Mephrin/A5-protein/PTPmu (MAM) and immunoglobulin domains in the extracellular region of the molecule mediate binding events between adjacent PTP $\mu$ molecules on the cell surface [19-21]. As with other adhesion molecules, oligomeric PTP $\mu$ molecules are thought to cluster within the plane of the cell membrane of one cell to form tight adhesions with РТР $\mu$ clusters on an adjacent cell. In contrast to healthy cells, aberrant, increased protease activity is often observed in tumor cells [22-24]. In the tumor setting, proteolysis of adhesion molecules disrupts cell-cell and cell-matrix adhesions, alters signaling events needed for contact inhibition and increases migratory behavior. We have previously shown 
that РТP $\mu$ is susceptible to cleavage in the tumor microenvironment and proteolysis of PTP $\mu$ contributes to enhanced growth and migration of tumor cells [25-27]. Proteolytic targeting of РТР $\mu$ leads to the disruption of normal РТР $\mu$-РТР $\mu$ interactions and results in the formation of an extracellular РTP $\mu$ fragment and thus a tumor specific biomarker. In previous work, we took advantage of the homophilic nature of PTP $\mu$ binding to identify PTP $\mu$-derived peptides that can be used to detect this PTP $\mu$ tumor biomarker when coupled to fluorophores [25]. In vitro studies using Texas Red-labeled PTP $\mu$ peptides demonstrated the presence of the РTP $\mu$ biomarker in tumor sections but not in normal tissues [25]. More recently, we found that in brain tumor patients, the PTP $\mu$ biomarker was a prognostic indicator [28]. Ex vivo studies have further illustrated the remarkable ability of these peptides to label the biomarker on invasive tumor cells that have migrated far away from the main tumor [29,30]. In light of these studies, we have generated PTP $\mu$ targeted NBs and characterized their ability to target and enhance the detectable US signal in tumors.

\section{Results}

Nanobubbles incorporating the PTP $\mu$-targeting peptide SBK2 or a scrambled version of the peptide ("Scrambled"), as non-targeting control NBs, were first compared in vitro. As shown in Figure 1, the PTP $\mu$-targeted and Scrambled NBs demonstrated size and concentration distributions that were nearly identical to the size and buoyancy distribution of NBs made without any peptide-conjugated lipids ("Plain"). The mean size and standard deviations were $272 \pm 89 \mathrm{~nm}, 285 \pm 104 \mathrm{~nm}$ and $248 \pm 85 \mathrm{~nm}$ for Plain, PTP $\mu$-targeted and Scrambled NB, respectively, for the representative preparations shown in Figure 1. The corresponding concentrations for these NBs were $2.03 \times 10^{11}, 1.99 \times 10^{11}$ and $2.38 \times 10^{11} \mathrm{NB} / \mathrm{mL}$. There were no significant differences in size or concentration for any of the NBs. All three NB types also showed comparable stability when subjected to contrast harmonic imaging in vitro (Figure 1d). As shown in Figure 1d, the in vitro US signals varied slightly initially, but by 3 min into the scans, all three NB types (Plain, PTP $\mu$-targeted and Scrambled) showed US signals of approximately $10 \mathrm{~dB}$ which were maintained throughout the scan time.

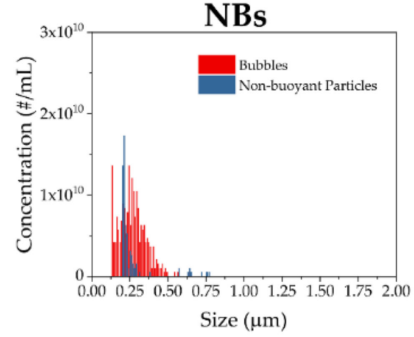

(a)

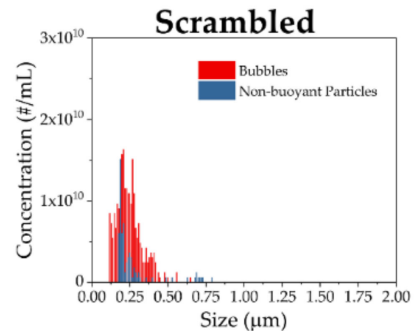

(c)

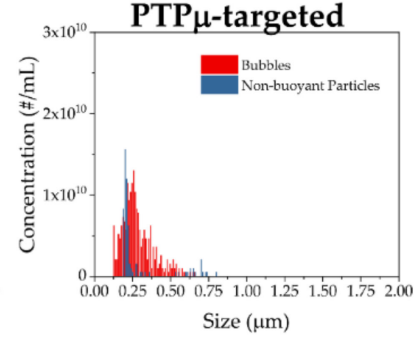

(b)

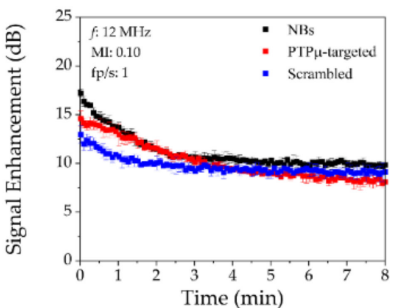

(d)

Figure 1. In vitro characterization of nanobubbles. The size and concentration distributions for (a) non-peptide modified nanobubbles (NBs), (b) Receptor Protein Tyrosine Phosphatase mu (PTP $\mu$ )targeted NBs and (c) Scrambled NBs measured using Archimedes resonant mass measurement are shown. (d) In vitro ultrasound characterization of the three different NB types. No significant differences were seen between the formulations. 
To ascertain baseline in vivo characteristics of the targeted and untargeted NBs, non-tumor bearing nude mice $(N=3)$ were injected with $100 \mu \mathrm{L}$ of one NB type $\left(2 \times 10^{11} \mathrm{NBs} / \mathrm{mL}\right)$ and US signals were collected simultaneously from the heart, liver and kidney for $30 \mathrm{~min}$. After $30 \mathrm{~min}$, residual NBs still present were destroyed by 3 high intensity ultrasound bursts, the animals were maintained under anesthesia for an additional $30 \mathrm{~min}$ to ensure clearance of all NBs and then $100 \mu \mathrm{L}$ of the alternate NB type was injected and imaging of the heart, kidney and liver repeated for $30 \mathrm{~min}$.

As shown in Figure 2, the two NB versions showed nearly identical signal enhancement and clearance in each of the three organs examined in the non-tumor bearing mice. Following injection, NB signals from either NB species were visible within $5 \mathrm{~s}$ in all three organs and peak contrast occurred by $5 \mathrm{~min}$ following the start of either NB injection. A gradual decrease in signal was observed in all three organs starting around $10 \mathrm{~min}$ and continued to decrease throughout the $30 \mathrm{~min}$ imaging window (Figure 2). At $30 \mathrm{~min}$, some signal above baseline was still evident for both types of bubbles in all three organs, which demonstrates similar in vivo stability and clearance in non-tumor bearing mice. As shown in Figure 2a, both NB types rapidly filled all tissues including the kidney, liver and heart. Analysis of time-intensity curves revealed slightly different values of maximum peak intensity among the three organs but the differences were not significant (Figure 2b). The maximum peak intensities reached by the Scrambled and PTP $\mu$-targeted NBs, respectively, were $19.3 \pm 0.6 \mathrm{~dB}$ and $20.4 \pm 2.1 \mathrm{~dB}$ in kidney, $17.3 \pm 2.5 \mathrm{~dB}$ and $19.0 \pm 0.7 \mathrm{~dB}$ in liver and $18.2 \pm 1.6 \mathrm{~dB}$ and $18.4 \pm 1.3 \mathrm{~dB}$ in heart.

Mice bearing РТP $\mu$ biomarker-expressing flank tumors were prepared as described to use for comparing the in vivo characteristics of PTP $\mu$-targeted and Scrambled NBs. After acquiring a standard B-mode image to properly align the imaging plane, the mode was switched to nonlinear contrast mode and, following a $1 \mathrm{~min}$ baseline acquisition, mice were injected with $200 \mu \mathrm{L}$ of a given type of NB $\left(2 \times 10^{11} \mathrm{NB} / \mathrm{mL}\right)$ over $45 \mathrm{~s}$ and imaged for a total of $30 \mathrm{~min}$. Figure 3 a shows images for a representative mouse imaged with both NB types. The CEUS signal after NB injection occurred rapidly with both PTP $\mu-$ targeted and untargeted NBs and filling of both kidney and tumor 5 min after scan start (4 min after NB injection) was evident (Figure 3a). Mean time intensity curves (TICs) from a total of $N=6$ mice treated with the Scrambled NB and $N=7$ mice treated with the PTP $\mu$-targeted NBs are shown in Figure $3 \mathrm{~b}$. Contrast enhancement in the tumor was apparent within $15 \mathrm{~s}$ of starting the NB injection and as shown in Figure $3 \mathrm{~b}$, peak tumor contrast occurred between 2 and 4 min of initiating the NB administration (3-5 min after the scan started) for both agents. Peak tumor signal occurred around 5 min for PTP $\mu$-targeted NBs while peak tumor signal for Scrambled NBs occurred slightly earlier, at around $4 \mathrm{~min}$. As shown in the upper panel of Figure 3b, PTP $\mu$-targeted NB tumor signal cleared more slowly over the $30 \mathrm{~min}$ imaging time than that of the Scrambled NB (Figure 3b). The kinetics of signal enhancement in kidney for the targeted and non-targeted NBs were similar with peak signal occurring around $3 \mathrm{~min}$ and persisting out to $10 \mathrm{~min}$ (Figure $3 \mathrm{~b}$, lower panel). Significantly higher signal was detected in kidney of the tumor-bearing mice treated with the PTP $\mu$-targeted NBs compared to the Scrambled NBs throughout this time (Figure $3 b$ ). These results suggest that the РТР $\mu$ biomarker may be present in kidneys. In contrast to tumor, the PTP $\mu$-targeted NB signal declined more rapidly in kidney, starting around $12 \mathrm{~min}$, compared to Scrambled NBs and both were near baseline levels by $30 \mathrm{~min}$. To more closely examine the differences in PTP $\mu$-targeted and untargeted NB clearance at later time points, normalized values were obtained by dividing the tumor signal by the kidney signal for each replicate and plotted (Figure 3c). As shown in Figure 3c, the tumor/kidney values for the PTP $\mu$-targeted NBs were $0.9 \pm 0.1$ at $10 \mathrm{~min}$ and continued to increase to $2.5 \pm 0.6$ at $30 \mathrm{~min}$. In contrast, the tumor/kidney values for the Scrambled NBs were $0.9 \pm 0.1$ at $10 \mathrm{~min}$ but decreased steadily to $0.6 \pm 0.2$ at $30 \mathrm{~min}$. During the last $5 \mathrm{~min}$ of scan time, the tumor/kidney values were significantly higher in mice receiving the PTP $\mu$-targeted NBs than in mice injected with the untargeted NBs, with the exception of the 27th min 
where $p=0.05$, indicating relatively more tumor signal persisted in those mice (Figure 3c, inset panel).

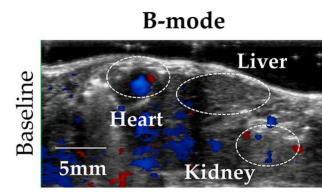

Scrambled NBs

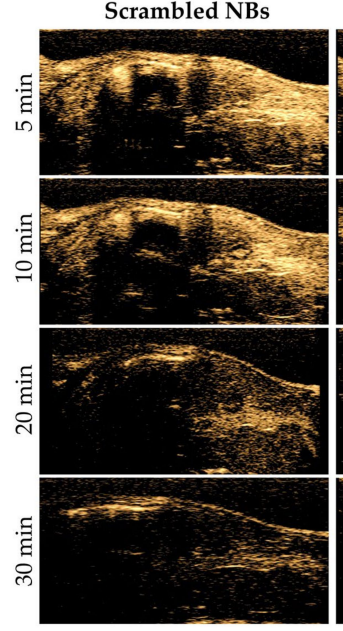

(a)

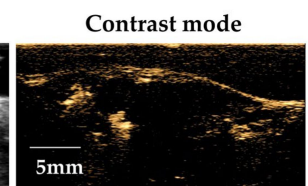

PTP $\mu$-targeted NBs

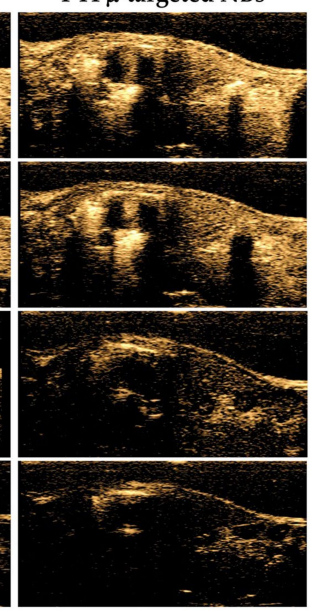

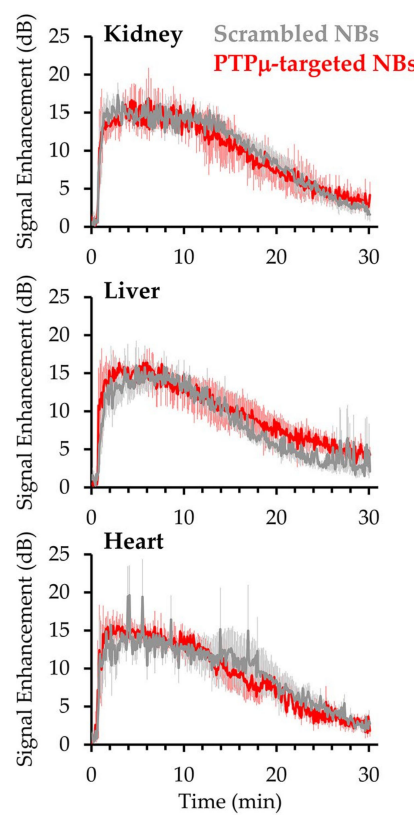

(b)

Figure 2. Ultrasound imaging of non-tumor bearing control mice treated with Scrambled and PTP $\mu$ targeted NBs. (a) Representative images of non-tumor bearing control mice administered Scrambled-NBs and PTP $\mu$-targeted NBs. The two NB types show similar enhancement of the heart, liver and kidneys at the times indicated. Top row shows a B-mode baseline image used for positioning (left) and a baseline contrast harmonic image (CHI) (right). Lower panels show heart, liver and kidney enhancement by the different NBs at the indicated times. (b) PTP $\mu$-targeted and non-targeted NB (Scrambled-NB) show similar kinetics of signal enhancement and gradual clearance in kidney, liver and heart in non-tumor bearing mice. Images of the three organs were collected simultaneously over $30 \mathrm{~min}$ in mice $(N=3)$ receiving both types of NB. Mean signal intensity \pm standard error are plotted for each organ type.

CEUS signals are inherently noisy. To better assess relative signal intensities of the two NB types for each region of interest (ROI), the 12 echo power values collected over a given minute were averaged and compared for each one-minute interval. Using this approach, the peak PTP $\mu$-targeted NB tumor signal of $17.4 \pm 1.4 \mathrm{~dB}$, occurred during the 5th minute while the peak Scrambled NB tumor signal, $13.6 \pm 1.6 \mathrm{~dB}$, occurred during the 4th minute. The mean PTP $\mu$-targeted NB tumor signal was more than $33 \%$ and significantly higher than the Scrambled NB signal from the 5th through 7th minute intervals. During these one-minute intervals, the mean PTP $\mu$-targeted signals were $17.4 \pm 1.4 \mathrm{~dB}, 17.1 \pm 1.4 \mathrm{~dB}$ and $16.3 \pm 1.3 \mathrm{~dB}$ compared to the corresponding Scrambled NB signals of $13.0 \pm 1.3 \mathrm{~dB}(p<0.05), 12.4 \pm 1.4 \mathrm{~dB}$ $(p=0.03)$ and $11.9 \pm 1.6 \mathrm{~dB}(p<0.05)$. Figure $4 \mathrm{a}$, upper panel, shows the mean tumor signals obtained from PTP $\mu$-targeted and Scrambled NBs at one-minute intervals corresponding to 5, 10, 20 and $30 \mathrm{~min}$. After peak enhancement, the tumor signal decreased for both types of NBs, but the PTP $\mu$-targeted NBs persisted in the tumor for longer and cleared more slowly than the Scrambled NBs. During the 25th min, the mean US signal for the PTP $\mu$-targeted NBs was $4.3 \pm 1.0 \mathrm{~dB}$ and the US signal for the Scrambled NBs was $2.1 \pm 0.6 \mathrm{~dB}$. During the 30th minute, the mean US signal from the PTP $\mu$-targeted NBs was more than $20 \%$ of the peak US intensity $(3.6 \pm 0.9 \mathrm{~dB})$ while the US signal from the Scrambled NBs was about $11 \%$ of that at the peak $(1.5 \pm 0.5 \mathrm{~dB})$. As shown in Figure $4 \mathrm{a}$, lower panel, the PTP $\mu$-targeted NB signal was also significantly higher than the Scrambled NB signal in kidney during the 5th and 10th minute intervals. The mean PTP $\mu$-targeted signals were $15.8 \pm 0.6 \mathrm{~dB}$ and $14.3 \pm 0.3 \mathrm{~dB}$, compared to the corresponding Scrambled NB signals of $12.0 \pm 0.7 \mathrm{~dB}(p<0.01)$ and $10.7 \pm 1.3 \mathrm{~dB}(p<0.05)$ 
for the 5th and 10th min, respectively. By $20 \mathrm{~min}$, the PTP $\mu$-targeted NB signal in kidney was less than that of the Scrambled NBs, although these values were not significantly different.

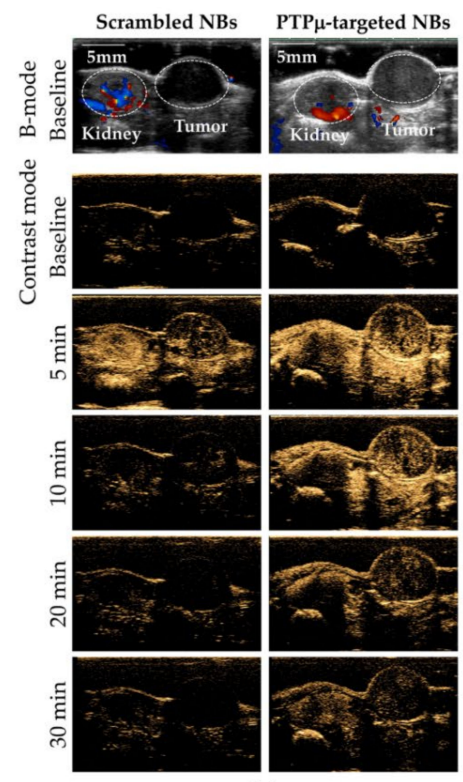

(a)
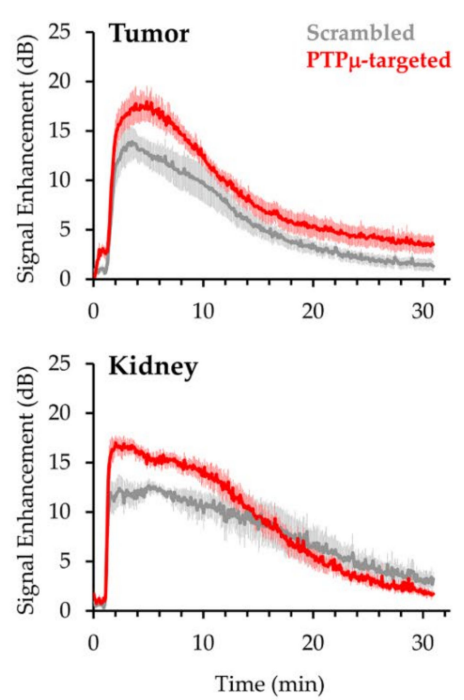

(b)

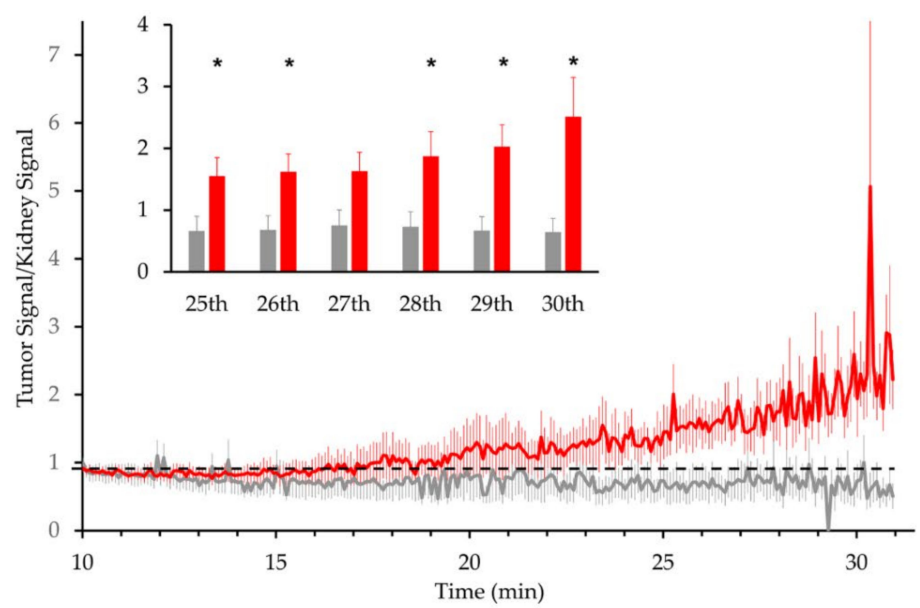

(c)

Figure 3. Ultrasound imaging of a representative tumor-bearing mouse treated with Scrambled and PTP $\mu$-targeted NBs and time intensity curves from the tumor-bearing mouse cohort after administering Scrambled and PTP $\mu$-targeted NBs. (a) In vivo US signal produced by the two NB types at various times. Baseline images in B-mode used for positioning and contrast mode images are shown for a representative mouse administered Scrambled NB (left) compared to PTP $\mu$-targeted NB (right) along with contrast mode images at indicated times following the start of the scan. NBs were injected at a rate of $0.26 \mathrm{~mL} / \mathrm{min}$ after acquiring a $1 \mathrm{~min}$ baseline. (b) The contrast harmonic signal measured over time in tumor (top plots) and kidney (bottom plots) in response to Scrambled-NB (gray) and PTP $\mu$-targeted NBs (red). $N=6$ for mice injected with Scrambled-NBs, $N=7$ for mice injected with PTP $\mu$-targeted NBs. Plots show mean signal intensity \pm standard error. (c) Tumor signal normalized to kidney signal for the mice shown in panel $(\mathbf{b})$ at later time points. PTP $\mu$-targeted NBs showed relatively slower clearance from the tumor towards the end of the scan time compared to Scrambled NBs. Plots show mean normalized value \pm standard error. Inset shows mean normalized values during the indicated one-minute intervals for the two NBs types $\left({ }^{*} p<0.05\right.$ as indicated for 25th-26th and 28th-30th minutes, $p=0.05$ for the 27th minute interval). During the 30th minute, the normalized PTP $\mu$-targeted NB value was 3.9-fold higher than that of the untargeted NBs. 

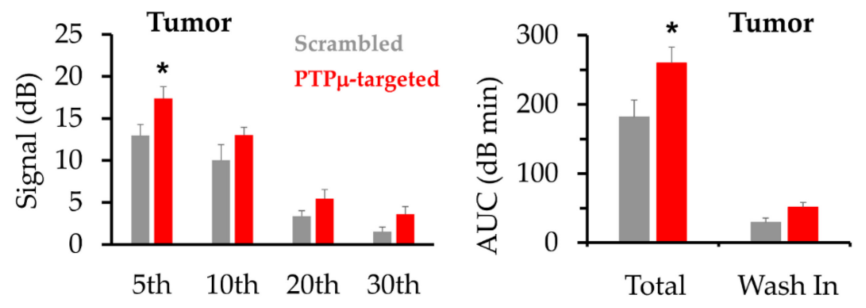

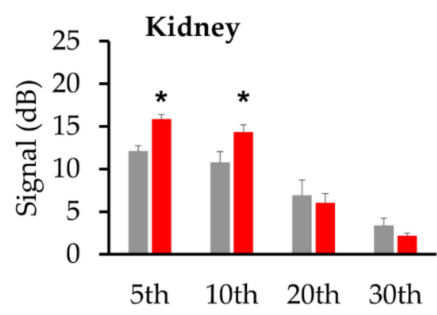

(a)

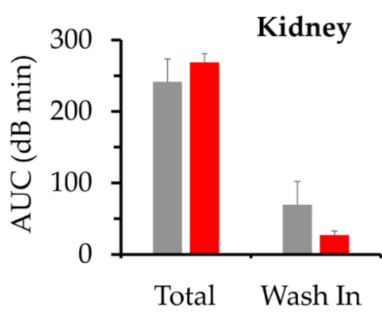

(b)

Figure 4. $\mathrm{PTP} \mu$-targeted NBs show greater contrast in tumors and are retained longer than Scrambled NBs. (a) The mean \pm standard error (SE) signal intensity was calculated from the 12 echo power measurements collected for each 1-minute increment for the data represented as time intensity curves (TICs) in 3b. In tumor, the US signal produced by PTP $\mu$-targeted NBs was significantly greater than that of the Scrambled NBs during the 5th through 7th minute increments. In kidney, the US signal produced by PTP $\mu$-targeted NB was significantly greater than that of the Scrambled NBs from the 3rd through 10th minute increments. (b) Area under the curve (AUC) parameters obtained from the TICs shown in 3b. In tumor, PTP $\mu$-targeted NBs had significantly higher total and $\mathrm{AUC}_{\text {wash-in }}$ compared to Scrambled NBs. In kidney, total AUC and $\mathrm{AUC}_{\text {wash-in }}$ were not significantly different between PTP $\mu$-targeted NB and Scrambled NBs. Bars represent the mean \pm SE of the AUC type indicated, $\left({ }^{*} p<0.05\right)$.

Parameters extracted from the aggregated TIC shown in Figure $3 \mathrm{~b}$ provided additional insights into the nature of the PTP $\mu$-targeted and Scrambled NBs enhancement and are depicted in Figure $4 \mathrm{~b}$ and Table 1. For tumors, the total area under the curve (AUC) as well as the $\mathrm{AUC}_{\text {wash-in }}$ were significantly higher after PTP $\mu$-targeted NB dosing, $260.1 \pm 23.1 \mathrm{~dB} \cdot \mathrm{min}$ and $51.5 \pm 6.8 \mathrm{~dB} \cdot \mathrm{min}$, respectively, compared to tumors following Scrambled NB dosing, $181.8 \pm 24.6 \mathrm{~dB} \cdot \min (p=0.04)$ and $29.4 \pm 6.4 \mathrm{~dB} \cdot \min (p=0.04)$, respectively. Significantly higher AUC indicated more prolonged enhancement of the tumors by the PTP $\mu$-targeted NB. AUC ${ }_{\text {wash-out }}$ was also higher in tumors treated with PTP $\mu$-targeted NBs, but the values were not significantly different (Table 1). As shown in Table 1, other parameters evaluated between the two NB types included the peak intensity, peak time, time for the peak to decrease by $50 \%\left(t_{50}\right)$ and the wash-out rate. In contrast to comparisons of mean signals made over $1 \mathrm{~min}$ intervals described above, these TIC parameters were based on the data acquired every $5 \mathrm{~s}$ during the scan. Although the absolute maximum peak intensity values of the two NB types were not significantly different (Table 1), it is nonetheless important that the mean signals determined over three consecutive $1 \mathrm{~min}$ intervals were significantly higher in tumors following PTP $\mu$-targeted NB treatment compared to tumors treated with Scrambled NBs. In kidney, the total AUC did not differ significantly between the PTP $\mu$-targeted and Scrambled NBs, indicating that overall kidney enhancement by PTP $\mu$-targeted NBs was not prolonged relative to the non-targeted NBs (Figure $4 \mathrm{~b}$, Table 1). Like total AUC, $\mathrm{AUC}_{\text {wash-in }}$ did not differ significantly in kidney between the two NB types, although $\mathrm{AUC}_{\text {wash-out }}$ was significantly higher following PTP $\mu$-targeted NB treatment compared to Scrambled NBs (Table 1). As shown in Table 1, kidney enhancement by PTP $\mu$-targeted and the non-targeted control NBs showed no significant differences in terms of peak time, $t_{50 \%}$, or wash-out rate. In contrast to these parameters, the peak signal intensity in kidney achieved by PTP $\mu$-targeted NBs was significantly higher than that obtained following Scrambled NB injection (Table 1). 
Table 1. Summary of parameters extracted from time intensity curves for tumor and kidney.

\begin{tabular}{|c|c|c|c|}
\hline & $\begin{array}{c}\text { Scrambled } \\
\text { Mean }( \pm \text { SE })\end{array}$ & $\begin{array}{c}\text { PTP } \mu \text {-Targeted } \\
\text { Mean }( \pm \text { SE })\end{array}$ & $p$-Value \\
\hline \multicolumn{4}{|l|}{ Tumor } \\
\hline $\operatorname{AUC}(\mathrm{dB} \cdot \min )$ & $181.8(24.6)$ & $260.1(23.1)$ & $0.04 *$ \\
\hline $\mathrm{AUC}_{\text {wash-in }}(\mathrm{dB} \cdot \mathrm{min})$ & $29.4(6.4)$ & $51.6(6.8)$ & $0.04 *$ \\
\hline $\mathrm{AUC}_{\text {wash-out }}(\mathrm{dB} \cdot \mathrm{min})$ & $152.4(22.8)$ & $208.5(22.6)$ & 0.11 \\
\hline Peak intensity $(\mathrm{dB})$ & $15.2(1.5)$ & $18.8(1.6)$ & 0.13 \\
\hline Peak time $\left(t_{\max }\right)(\mathrm{min})$ & $3.9(0.7)$ & $5.2(0.7)$ & 0.23 \\
\hline Time to reach $50 \%$ of peak $\left(t_{50 \%}\right)(\mathrm{min})$ & $12.3(1.5)$ & $15.1(2.7)$ & 0.40 \\
\hline Wash-out rate $(\Delta \mathrm{dB} / \mathrm{min})$ & $-1.0(0.3)$ & $-1.1(0.2)$ & 0.84 \\
\hline \multicolumn{4}{|l|}{ Kidney } \\
\hline $\operatorname{AUC}(\mathrm{dB} \cdot \min )$ & $241.6(31.6)$ & $268.9(11.8)$ & 0.41 \\
\hline $\mathrm{AUC}_{\text {wash-in }}(\mathrm{dB} \cdot \mathrm{min})$ & $69.6(32.3)$ & $26.8(5.9)$ & 0.19 \\
\hline $\mathrm{AUC}_{\text {wash-out }}(\mathrm{dB} \cdot \mathrm{min})$ & $172.0(28.3)$ & $242.1(11.9)$ & 0.03 * \\
\hline Peak intensity (dB) & $15.5(1.1)$ & $18.2(0.6)$ & 0.04 * \\
\hline Peak time (min) & $7.4(2.9)$ & $2.9(0.5)$ & 0.13 \\
\hline Time to reach $50 \%$ of peak $\left(t_{50 \%}\right)(\mathrm{min})$ & $17.8(3.2)$ & $16.5(1.4)$ & 0.69 \\
\hline Wash-out rate $(\Delta \mathrm{dB} / \mathrm{min})$ & $-0.6(0.1)$ & $-0.5(0.1)$ & 0.44 \\
\hline
\end{tabular}

*Significantly different $(p<0.05)$.

The differences detected in CEUS mediated by the PTP $\mu$-targeted and Scrambled NBs suggested vascular targeting. Therefore, we performed immunohistochemistry to determine the distribution of the РТР $\mu$ biomarker relative to endothelial cells in both tumor and kidney. LN-229 tumors and kidneys were harvested from tumor-bearing mice, formalin-fixed, processed and stained with reagents specific for the РTP $\mu$ biomarker and for $\mathrm{N}$-acetylglucosamine, a carbohydrate group found in abundance on endothelial cells, using fluorescein isothiocyanate (FITC)-labeled tomato lectin (Lycopersicon esculentum) [31]. As shown in Figure 5, the РТP $\mu$ biomarker was present throughout the tumor and also appeared uniformly distributed on the surfaces of vascular structures (Figure 5, upper row, boxed areas). Tomato lectin labeled the same vascular structures (Figure 5, upper row, boxed areas) as SBK4-TR, the PTP $\mu$ biomarker specific agent, as well as other parts of the tumor. In kidney, the most intense SBK4-TR staining was of vascular structures similar to those recognized by the tomato lectin (Figure 5, bottom row, boxed area).

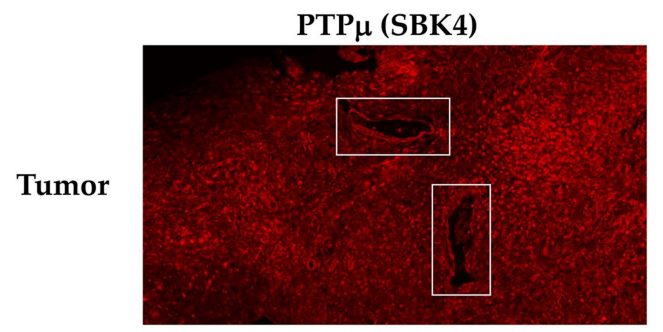

Tomato Lectin (Blood Vessels)

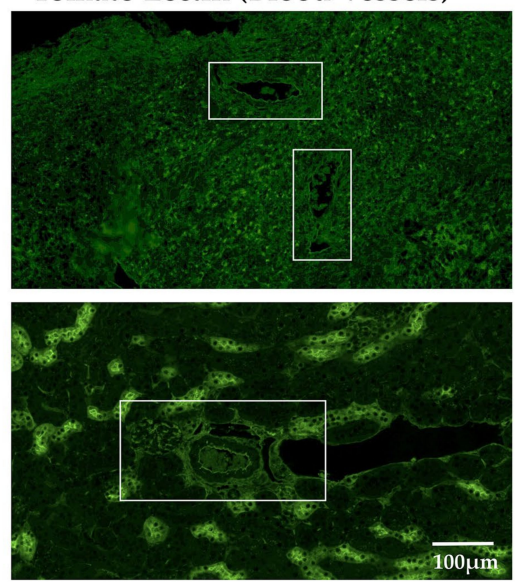

Figure 5. Localization of the PTP $\mu$ biomarker and endothelial cells in tumor and kidneys. Tumors and kidneys were obtained from mice bearing LN-229 flank tumors, fixed and stained with SBK4-TR, a peptide agent specific for the $\mathrm{PTP} \mu$ biomarker and fluorescein isothiocyanate (FITC)-labeled tomato lectin. The top left panel shows high levels of the РTP $\mu$-biomarker throughout the tumor, as well as on the surface of vascular structures (boxed areas). Diffuse tomato lectin staining (top right panel) was found throughout the tumor as well as on the same vascular surfaces (boxed areas) as the РТР $\mu$ biomarker. Less of the PTP $\mu$ biomarker was detected overall in the kidney (lower left panel), compared to tumor, but the vasculature showed high levels of the biomarker (boxed area). Tomato lectin stained vascular structures, similar to the bright SBK4-TR areas, as well as distinct cells throughout the kidney. All images were acquired at the same scale shown in the lower right panel. 


\section{Discussion}

For this study, we utilized NBs based on the highly stable formulation described by de Leon and colleagues [18], along with a PTP $\mu$-targeting peptide to examine targeting and contrast enhancement in a tumor model relative to non-specific NBs. In vitro and in non-tumor bearing control mice, both NB types showed equivalent signal enhancement characteristics in heart, kidney and liver. In vivo, PTP $\mu$ biomarker-rich flank tumors showed more signal enhancement throughout the tumor and more sustained signal enhancement with the PTP $\mu$-targeted NBs relative to the Scrambled-NB control agent. In these experiments the kidneys of tumor-bearing mice, but not non-tumor-bearing control mice, showed significantly higher nonlinear peak signal following treatment with PTP $\mu$-targeted NBs compared to the Scrambled NBs. We have not previously observed any differences in kidney targeting or enhancement between PTP $\mu$-targeted and Scrambled imaging agents in other imaging modalities such as MRI or fluorescence imaging (MJ, JAV, SBK, unpublished observations). It is possible that the combination of real time image acquisition and the nature of the NBs used in US allowed the detection of the PTP $\mu$-biomarker in the kidneys of these tumor-bearing mice. The other methods mentioned (fluorescence imaging and MRI) require longer image acquisition times and use agents where the targeting peptide is in a 1:1 molar ratio with the moiety used for detection. In both of these modalities, the moiety conferring the signal (i.e., fluorophore or gadolinium chelate) provides a detectable signal both while binding to the tumor and after clearance into the kidney and eventually bladder. The total signal provided by the contrast agent will remain essentially constant but will be redistributed throughout the body as time elapses, eventually accumulating in the renal system until the mouse wakes up and can void. Under these circumstances, it is possible that specific interactions of both fluorophore-peptides and gadolinium-chelate-peptides with kidney are obscured by the clearance of either excess agent or agent that has bound and released from tumor. In contrast, US contrast agents such as the PTP $\mu$-targeted NBs used in these studies only provide a detectable signal while they are intact NBs. The signal provided by the administered contrast agent, in this case PTP $\mu$-targeted NBs, continually decreases as NBs are destroyed in response to the pressures encountered in the ultrasound field. Remnants of NBs clearing through the renal system after binding to the tumor will not provide a detectable signal with the potential to obscure a kidney-specific signal. Thus, these CEUS studies have provided an opportunity to detect a potential kidney interaction with PTP $\mu$-targeted agents that we were unable to detect in our previous studies. In addition, each individual NB has many targeting peptides, unlike the fluorophore-peptide or gadolinium-chelate-peptides used in our previous studies. The binding characteristics of NBs may differ from those of the other agents and facilitate the visualization of kidney binding. To better understand what may account for the greater kidney enhancement with PTP $\mu$-targeted NBs compared with Scrambled NBs, we looked for the presence of the PTP $\mu$ biomarker in kidneys of tumor bearing mice. As shown in Figure 5, the PTP $\mu$ biomarker and endothelial cells were found in close proximity in particular areas of the kidney. It is possible that the circulation of PTP $\mu$-targeted NBs through the kidney facilitates the interaction of PTP $\mu$-targeted NBs with the PTP $\mu$ biomarker in this organ, leading to enhanced US signals shortly after injection of the PTP $\mu$-targeted NBs. Soluble forms of some cell adhesion molecules can circulate at detectable levels in many types of cancer patients [32-36]. Since the PTP $\mu$ biomarker is formed in response to proteolytic events, it is possible that it too might be taken up by the circulatory system in a soluble form. As a clearance organ, the kidney could potentially filter and concentrate any soluble PTP $\mu$ biomarker released from РTP $\mu$-enriched tumors resulting in the kidney being recognized by РTP $\mu$-targeted NBs. We note that despite the significantly higher nonlinear signal observed in the kidneys of these tumor-bearing mice following treatment with the PTP $\mu$-targeted NBs, there was no significant difference in AUC derived from TICs of the two NB types suggesting that the PTP $\mu$-targeted NBs were not retained to a significantly greater extent in the kidney relative to the control agent. Nonetheless, this is an intriguing finding that we plan to study further. 
These results are consistent with prior studies using a similar NB formulation but targeted to the prostate specific membrane antigen (PSMA) [11]. Specifically, in both studies, the NBs targeted to PSMA show similar slower washout kinetics and greater tumor retention at the end point of the study compared to NBs without a targeting ligand. However, in contrast to the PSMA biomarker, which is expressed only on prostate cancer cells, РТP $\mu$ is expressed on endothelial cells and specifically found at cellular junctions which mediate paracellular permeability and potentially extravasation [37-40]. We hypothesize that this difference in biomarker expression is responsible for the distinctly higher peak intensity of the PTP $\mu$-targeted NBs compared to untargeted NBs. When imaging PSMA, this difference is not seen and peak intensity of both types of bubbles is nearly identical. This could be an exciting indicator that targeted NBs can, in real time, recognize biomarker distribution and display binding kinetics. Furthermore, the binding of NBs to the endothelium would likely reduce the fraction of NBs which extravasate into the tumor parenchyma. This could be the reason for a relatively smaller difference in the targeted versus untargeted NB retention in this model compared to PSMA-targeted NBs. This is also supported by the latent increase in tumor signal compared to kidney signal observed for the PTP $\mu$-targeted NBs. In this model, the tumor signal does not increase perceivably until 15 min after bubble injection. In contrast, the same parameter in PSMA-targeted NBs shows a rapid increase after $5 \mathrm{~min}$. This may be a result of decreased endothelial bubble binding in the latter portion of the scan. Taken together, these data demonstrate that PTP $\mu$-targeted NBs can effectively target PTP $\mu$ and persist in tumors. In addition to its use in echocardiography and other settings, US is often the first imaging modality employed in the diagnosis of ovarian cancer [41]. We have recently detected high levels of the PTP $\mu$ biomarker in several types of gynecological cancers including high grade serous ovarian cancer [42]. Our future plans include utilizing mouse models of multiple types of cancer along with our PTP $\mu$-targeted NBs to expand these findings and to utilize PTP $\mu$-targeted $\mathrm{NB}$ as theranostics.

In summary, PTP $\mu$-targeted NBs demonstrated excellent stability both in vitro and in vivo. In models of tumor imaging in vivo, PTP $\mu$-targeted NBs showed increased contrast throughout the tumor and greater peak contrast when compared to non-targeted ScrambledNBs. Enhanced signal was detectable in tumor within $15 \mathrm{~s}$ of initiating the injection of either NB type, but PTP $\mu$-targeted NBs showed significantly higher signal compared to Scrambled NBs at peak contrast which occurred throughout a 5-7 min interval following the start of the scan. At later time points the contrast enhanced signal was also higher using PTP $\mu$-targeted NBs relative to the control agent. In addition, the total AUC value derived from the PTP $\mu$-targeted TIC was significantly higher than the total AUC from Scrambled TIC, further demonstrating effective tumor enhancement by the PTP $\mu$-targeted NBs. Based on these studies, the use of PTP $\mu$-targeted NBs for diagnostic and theranostic use warrants further investigation.

\section{Materials and Methods}

\subsection{Materials}

Nanobubbles were made from a combination of 1,2-dibehenoyl-sn-glycero-3- phosphocholine (DBPC), 1,2-dipalmitoyl-sn-glycero-3-phosphate (DPPA) and 1,2-dipalmitoylsn-glycero-3-phosphoethanolamine (DPPE), all purchased from Avanti Polar Lipids, Pelham, AL, USA, along with 1,2-distearoyl-sn-glycero-3-phosphoethanolamine-N-(methoxy (polyethylene glycol)-2000) (ammonium salt) (DSPE-mPEG 2000) from Laysan Lipids, Arab, AL, USA. The lipids were dissolved in propylene glycol (PG, Sigma Aldrich, Milwaukee, WI, USA), glycerol (Acros Organics) and Gibco phosphate buffered saline (PBS, pH 7.4,1×) from Thermo Fisher, Waltham, MA, USA.

\subsection{Peptide-Lipid Conjugation}

The SBK2 (GEGDDFNWEQVNTLTKPTSD) and Scrambled (GTQDETGNFDWPVSEDLNKT) peptides were synthesized on a CS Bio CS336X Synthesizer as described previ- 
ously [43] using Fmoc-protected amino acids purchased from either Chem-Impex, Wood Dale, IL, USA or Aapptec, Louisville, KY, USA. An N-terminal cysteine was included along with a six amino acid spacer (GGSGGS) to allow conjugation of the peptides to 1,2-distearoyl-sn-glycero-3phosphoethanolamine-N-(methoxy (polyethylene glycol)-2000)-maleimide (DSPE-PEG-MAL) Laysan Bio, Arab, AL via a thiol-maleimide reaction. Peptides were conjugated to DSPEPEG-MAL by thoroughly mixing peptide with lipid in PBS, pH 8.0 in a 1:2 molar ratio and incubating the reaction for $2 \mathrm{~h}$ at room temperature. The reaction mixture was checked by reverse phase high performance liquid chromatography (HPLC) on a Shimadzu HPLC system equipped with an SPD-20A Prominence UV/visible detector and monitored at $220 \mathrm{~nm}$ and $254 \mathrm{~nm}$ using a Luna $5 \mu \mathrm{C} 18$ (2) $100 \mathrm{~A}$ column $(250 \mathrm{~mm} \times 46 \mathrm{~mm} \times 5 \mathrm{~mm}$, Phenomenex, Torrance, CA) at a flow rate of $0.8 \mathrm{~mL} / \mathrm{min}$ (Figure S1). The mobile phase was $10-90 \%$ acetonitrile versus water with $0.1 \%$ trifluoroacetic acid over $30 \mathrm{~min}$ [11]. After confirming that no unreacted peptide remained in the mixture, the reaction was lyophilized. The lyophilized product was dissolved in PBS to make a stock solution of $1 \mathrm{mg} / \mathrm{mL}$ concentration to use in making the nanobubbles. Matrix-assisted laser desorption/ionization time-of-flight mass spectroscopy (MALDI-TOF-MS) was also performed to confirm the successful conjugation of the peptides to DSPE-PEG-MAL using $20 \mathrm{mg} / \mathrm{mL}$ 2,5-dihydroxybenzoic acid in 50\% acetonitrile $/ 50 \%$ water with $0.1 \%$ trifluoroacetic acid as matrix. These analyses were performed by the Center of Materials and Sensor Characterization at the University of Toledo, Toledo, OH, USA on a Bruker UltrafleXtreme MALDI TOF/TOF Mass spectrometer (Figure S2).

\subsection{Nanobubble Formulation}

Nanobubbles were formulated as previously described [11,44]. A lipid mixture consisting of $6.1 \mathrm{mg}$ of DBPC, $2 \mathrm{mg}$ of DPPE, $1 \mathrm{mg}$ of DPPA and $1 \mathrm{mg}$ of mPEG-DSPE was dissolved in $0.1 \mathrm{~mL}$ of propylene glycol in a sonicating water bath heated to $80^{\circ} \mathrm{C}$. For PTP $\mu$-targeted or Scrambled NBs, $75 \mu \mathrm{g}$ of either DSPE-PEG-SBK2 or DSPE-PEG-Scrambled from the stock solutions described above were added to the DBPC/DPPE/DPPA/mPEG-DSPE cocktail. In a separate container, $0.8 \mathrm{~mL}$ of PBS (pH 7.4) and $0.1 \mathrm{~mL}$ of glycerol were combined and warmed to $80^{\circ} \mathrm{C}$ and then added to the lipid solution. After $10 \mathrm{~min}$ in a room temperature sonicating water bath, the solution was placed in a $3 \mathrm{~mL}$ headspace vial, capped with a rubber stopper and sealed with an aluminum cap. The air within the vial headspace was replaced with octafluoropropane gas (AirGas, Cleveland, OH, USA). Bubbles were formed by agitation of the vial with a VialMix mechanical shaker for $45 \mathrm{~s}$. After centrifugation for 5 min at $50 \times g$, nanobubbles were collected with a syringe $(21 \mathrm{G} \times 1 \mathrm{in}$.) from the bubble fraction within $0.5 \mathrm{~cm}$ of the stopper, as described previously [44].

\subsection{In Vitro Nanobubble Characterization}

The nanobubble size and concentration were measured using resonant mass measurement (RMM) (Archimedes, Malvern Panalytical Inc., Westborough, MA, USA) [44]. A nanosensor, which can measure particle size between $100 \mathrm{~nm}$ and $2 \mu \mathrm{m}$, was used to measure the particles and calibrated using National Institute of Standards and Technology (NIST) traceable $565 \mathrm{~nm}$ polystyrene bead standards (ThermoFisher 4010S, Waltham, MA, USA). The NBs were diluted (1:1000) with PBS, $\mathrm{pH} 7.4$ prior to measurement.

In vitro US stability of the nanobubbles was assessed using an AplioXG SSA-790A ultrasound instrument (Toshiba Medical Imaging Systems, Ottaware-Shi, Japan) and a custom-made $1.5 \%(w / v)$ agarose mold with a triple channel $(\mathrm{L} \times \mathrm{W} \times \mathrm{H}$ per channel $=5 \mathrm{~mm} \times 3 \mathrm{~mm} \times 6 \mathrm{~mm}$ ) and imaged for $8 \mathrm{~min}$. Acquisition parameters included contrast harmonic imaging $(\mathrm{CHI})$ with $12.0 \mathrm{MHz}$ harmonic frequency, 0.1 mechanical index (MI), $65 \mathrm{~dB}$ dynamic range and $70 \mathrm{~dB}$ gain. The ultrasound signal was determined using the pre-loaded quantification software (CHI-Q). Samples were diluted 1:100 in PBS, pH 7.4 prior to imaging. 


\subsection{Mice and Experimental Tumor Models}

National Institutes of Health (NIH) athymic nude female mice (NCr-nu/+, NCr-nu/nu) were bred in the Case Western Reserve University Athymic Animal Core Facility. Tumors were initiated in mice at approximately 6 weeks of age. Human LN-229 tumor cells were chosen for these studies as a model tumor type expressing the РТP $\mu$ biomarker and have been used in previous imaging studies to examine PTP $\mu$-targeted agents $[25,30]$. These cells were obtained from the American Type Culture Collection (Manassas, VA, USA) and cultured as previously described [25]. Cells were mixed with Matrigel Matrix (Corning, Corning Inc., Corning, NY, USA) and $2 \times 10^{6}$ cells were injected into the right flank of each mouse. Mice were used for in vivo experiments when tumors were between 44 and $58 \mathrm{~d}$ old. The mean (SE) tumor age for mice receiving targeted NBs was 50.3 (2.2) $\mathrm{d}$ and for mice receiving the untargeted NBs, the mean (SE) was 50.3 (4.5) days. Tumor volumes calculated using the formula (length $\times$ width $\left.{ }^{2}\right) / 2$ were $457.8(116.8) \mathrm{mm}^{3}$ and $512.5(95.7) \mathrm{mm}^{3}$ for the tumors used with PTP $\mu$-targeted and Scrambled NBs, respectively, and were not significantly different using a two-tailed $t$-test $(p=0.78)$. For some experiments, athymic nude mice without tumors were used for in vivo experiments between the ages of 6 and 8 weeks.

\subsection{In Vivo US Imaging}

An Aplio XG SSA-790A Toshiba Medical Imaging Systems (now Hitachi) clinical ultrasound imaging system equipped with a $12 \mathrm{MHz}$ linear array transducer was used for these experiments. For US imaging of tumor-bearing mice, animals were anesthetized with $2-3 \%$ isoflurane with $1 \mathrm{~L} / \mathrm{min}$ oxygen and positioned on their left lateral sides on a $37^{\circ} \mathrm{C}$ platform. A PLT-1204BT ultrasound probe was positioned along the longitudinal axis to capture signals from both the tumor and kidney and clamped into position using B-mode imaging information. Changes in tissue contrast over time were measured using contrast harmonic imaging $(\mathrm{CHI})$ with harmonic receive frequency set to $12.0 \mathrm{MHz}$, mechanical index (MI) set to 0.10 , a dynamic range of $65 \mathrm{~dB}$, gain at $70 \mathrm{~dB}$ and the imaging frame rate set to $0.2 \mathrm{frame} / \mathrm{s}$. The images were acquired in the raw data format [45]. Baseline values were acquired for $60 \mathrm{~s}$ before intravenous administration of $200 \mu \mathrm{L}\left(2 \times 10^{11} \mathrm{NB} / \mathrm{mL}\right)$ of either the PTP $\mu$-targeted NBs or the Scrambled NBs via a tail vein catheter. NB injections occurred at the rate of approximately $0.26 \mathrm{~mL} / \mathrm{min}$. Animals were imaged for $30 \mathrm{~min}$ following injection. Most animals received both types of NBs in separate scans in random order and these in vivo experiments were separated by $5-10 \mathrm{~d}$. In total, $N=6$ for mice treated with the Scrambled NBs and $N=7$ mice were scanned with the PTP $\mu$-targeted NBs.

In vivo experiments in non-tumor bearing mice $(N=3)$ were performed in a similar manner with the exception that animals were positioned on their backs to allow the probe to capture signal from heart, liver and kidney. For these experiments, $100 \mu \mathrm{L}$ of both types of NB were administered on a given day but separated by at least $60 \mathrm{~min}$. After injection of one NB type, the animal was imaged for $30 \mathrm{~min}$, subjected to 3 high intensity ultrasound bursts to destroy NBs remaining in circulation and maintained in position for another 30 min to allow any residual NBs to clear before administering the other NB type and monitoring for $30 \mathrm{~min}$.

Software provided by Toshiba was used to process the acquired linear raw data images as has been described previously [11,45]. ROIs outlining the kidney and tumor were drawn on each mouse on the contrast mode image using the B-mode image as reference to avoid regions of skin and major blood vessels and the mean echo power value as a function of time was determined for each ROI type and exported to Microsoft Excel. Twelve echo power values were obtained per minute, corresponding to one value every $5 \mathrm{~s}(0.083 \mathrm{~min})$. The lowest signal value obtained for each ROI during an imaging session was used as the baseline value for that ROI and subtracted from the other echo power values recorded during the scan to generate the time-intensity curves (TIC). To examine NB clearance at later time points, tumor signal was normalized to the signal in kidney for each mouse by dividing the tumor signal by the kidney signal at each time point. The means (SEs) were plotted for each cohort. For comparison of US signals at different time intervals, the mean 
of the 12 echo power signals acquired over a given minute for each animal were used to represent the US signal for that animal during that minute. As indicated below, significance was determined using two-tailed $t$-tests.

\subsection{Histology}

Tumors and kidneys were harvested from mice with approximately 40-d old LN229 flank tumors, fixed in 10\% neutral-buffered formalin (Sigma-Aldrich, St. Louis, MO, USA) and paraffin embedded before making $5 \mu \mathrm{m}$ tissue sections. Tissue sections were stained for the PTP $\mu$ biomarker using the SBK4 peptide conjugated to Texas Red as has been previously described [28], in parallel to sections stained with the control Texas Redconjugated Scrambled peptide. FITC-labeled tomato lectin (Vector Laboratories, Inc., Burlingame, CA, USA), which binds N-acetylglucosamine present on endothelial cells [31], was used according to the manufacturer's directions to stain blood vessels. After staining, sections were mounted with Vectashield Hard Set Mounting Medium (Vector Laboratories, Inc. Burlingame, CA, USA), coverslipped and imaged with a Hamamatsu Nanozoomer S60 Slide Scanner (Hamamatsu Photonics, K.K., Bridgewater, NJ, USA).

\subsection{Statistical Analysis}

Microsoft Excel and OriginLab Origin were used for graphing and statistical analyses. Where indicated, unpaired two-tailed Student's $t$-tests were used to compare the two groups. Various TIC parameters such as area under the curve (AUC), time to peak, peak intensity and wash-out rate were calculated in Origin and have been used previously to describe and assess contrast enhanced US [2,11,46]. Briefly, peak intensity is the maximum signal measured in an ROI during a scan, time to peak is the amount of time in minutes from the initiation of the scan to the peak signal, $\mathrm{AUC}_{\text {wash-in }}$ represents the $\mathrm{AUC}$ from injection start to the peak signal and $\mathrm{AUC}_{\text {wash-out }}$ is the $\mathrm{AUC}$ from peak signal to scan end. Wash-out rate was determined by measuring the slope of the TIC between maximum peak intensity to half peak height. Peak intensity and time to peak values extracted from the TIC curves and based on the data acquired every $5 \mathrm{~s}$ vary slightly from similar parameters determined by averaging the signal over one-minute increments as described above used to compare data at minute intervals. Data are presented as mean \pm standard error (SE). The number of replicates is indicated for each experiment.

Supplementary Materials: The following are available online at https://www.mdpi.com/1422 $-0067 / 22 / 4 / 1983 / s 1$. Figure S1: Conjugation of the Scrambled and SBK2 peptides to the lipid DSPE-PEG-maleimide, Figure S2: MALDI-TOF MS analysis of DSPE-PEG-SBK2 and DSPE-PEGScrambled conjugates.

Author Contributions: Conceptualization, S.M.B.-K. and A.A.E.; methodology, M.L.J., R.P., E.A., X.W., J.V., A.A.E. and S.M.B.-K.; investigation, M.L.J., R.P., E.A., X.W. and J.V.; formal analysis, M.L.J., R.P. and E.A.; data curation, M.L.J. and R.P.; writing—original draft preparation, M.L.J.; writingreview and editing, M.L.J., R.P., E.A., X.W., J.V., A.A.E. and S.M.B.-K.; funding acquisition, A.A.E. and S.M.B.-K. All authors have read and agreed to the published version of the manuscript.

Funding: This research was supported with funding from The Mary Kay Foundation (Brady-Kalnay and Exner). This publication was made possible by support from the Clinical and Translational Science Collaborative of Cleveland (Brady-Kalnay and Exner), 4UL1TR000439 from the National Center for Advancing Translational Sciences (NCATS) component of the National Institutes of Health and NIH roadmap for Medical Research. Additional support was provided to the Brady-Kalnay laboratory by the National Institutes of Health sponsored Cancer Imaging Program of the Case Comprehensive Cancer Center and their core (P30CA043703). The Exner lab is also supported by the National Institutes of Health (R01EB025741). Views and opinions of and endorsements by the author(s) do not reflect those of the National Institutes of Health. 
Institutional Review Board Statement: All applicable institutional and/or national guidelines for the care and use of animals were followed. The mice used for these studies were included in animal protocol \#2015-0033, approved by the Case Western Reserve University Institutional Animal Care and Use Committee on 27 March 2018.

Informed Consent Statement: Not applicable.

Data Availability Statement: The data that support the findings of this study are available from the corresponding author upon reasonable request.

Acknowledgments: We thank Cathy Doller from the Visual Sciences Research Center Core for technical assistance with histology. We also acknowledge the support of the Light Microscopy Imaging Core of the School of Medicine and the technical support of Richard Lee.

Conflicts of Interest: Susann M. Brady-Kalnay is involved in the biotechnology company NeoIndicate. The other authors declare that they have no conflict of interest.

\section{References}

1. Szabo, T.L. Diagnostic Ultrasound Imaging: Inside Out, 2nd ed.; Elsevier: Amsterdam, The Netherlands, 2014.

2. Abou-Elkacem, L.; Bachawal, S.V.; Willmann, J.K. Ultrasound molecular imaging: Moving toward clinical translation. Eur. J. Radiol. 2015, 84, 1685-1693. [CrossRef]

3. De Leon, A.; Perera, R.; Nittayacharn, P.; Cooley, M.; Jung, O.; Exner, A.A. Ultrasound Contrast Agents and Delivery Systems in Cancer Detection and Therapy. Adv. Cancer Res. 2018, 139, 57-84. [CrossRef] [PubMed]

4. Erlichman, D.B.; Weiss, A.; Koenigsberg, M.; Stein, M.W. Contrast enhanced ultrasound: A review of radiology applications. Clin. Imaging 2020, 60, 209-215. [CrossRef] [PubMed]

5. Bierig, S.M.; Jones, A. Accuracy and Cost Comparison of Ultrasound Versus Alternative Imaging Modalities, Including CT, MR, PET, and Angiography. J. Diagn. Med. Sonogr. 2009, 25, 138-144. [CrossRef]

6. Hunt, D.; Romero, J. Contrast-Enhanced Ultrasound. Magn. Reson. Imaging Clin. N. Am. 2017, 25, 725-736. [CrossRef]

7. Caskey, C.F. Ultrasound Molecular Imaging and Drug Delivery. Mol. Imaging Biol. 2017, 3, 336-340. [CrossRef]

8. Kosareva, A.; Abou-Elkacem, L.; Chowdhury, S.; Lindner, J.R.; Kaufmann, B.A. Seeing the Invisible-Ultrasound Molecular Imaging. Ultrasound Med. Biol. 2020, 46, 479-497. [CrossRef] [PubMed]

9. Hyvelin, J.-M.; Gaud, E.; Costa, M.; Helbert, A.; Bussat, P.; Bettinger, T.; Frinking, P. Characteristics and Echogenicity of Clinical Ultrasound Contrast Agents: An In Vitro and In Vivo Comparison Study. J. Ultrasound Med. 2017, 36, 941-953. [CrossRef]

10. Lindner, J.R. Contrast echocardiography: Current status and future directions. Heart 2021, 107, 18-24. [CrossRef] [PubMed]

11. Perera, R.H.; De Leon, A.; Wang, X.; Wang, Y.; Ramamurthy, G.; Peiris, P.; Abenojar, E.; Basilion, J.P.; Exner, A.A. Real time ultrasound molecular imaging of prostate cancer with PSMA-targeted nanobubbles. Nanomed. Nanotechnol. Biol. Med. 2020, 28, 102213. [CrossRef] [PubMed]

12. Fan, X.; Guo, Y.; Wang, L.; Xiong, X.; Zhu, L.; Fang, K. Diagnosis of prostate cancer using anti-PSMA aptamer A10-3.2-oriented lipid nanobubbles. Int. J. Nanomed. 2016, 11, 3939-3950. [CrossRef] [PubMed]

13. Pochon, S.; Tardy, I.; Bussat, P.; Bettinger, T.; Brochot, J.; Von Wronski, M.; Passantino, L.; Schneider, M. BR55: A Lipopeptide-Based VEGFR2-Targeted Ultrasound Contrast Agent for Molecular Imaging of Angiogenesis. Investig. Radiol. 2010, 45, 89-95. [CrossRef]

14. Pysz, M.A.; Foygel, K.; Rosenberg, J.; Gambhir, S.S.; Schneider, M.; Willmann, J.K. Antiangiogenic Cancer Therapy: Monitoring with Molecular US and a Clinically Translatable Contrast Agent (BR55). Radiology 2010, 256, 519-527. [CrossRef]

15. Stride, E.; Segers, T.; Lajoinie, G.; Cherkaoui, S.; Bettinger, T.; Versluis, M.; Borden, M. Microbubble Agents: New Directions. Ultrasound Med. Biol. 2020, 46, 1326-1343. [CrossRef] [PubMed]

16. Roovers, S.; Segers, T.; Lajoinie, G.; Deprez, J.; Versluis, M.; De Smedt, S.C.; Lentacker, I. The Role of Ultrasound-Driven Microbubble Dynamics in Drug Delivery: From Microbubble Fundamentals to Clinical Translation. Langmuir 2019, 35, 1017310191. [CrossRef]

17. Lee, H.; Kim, H.; Han, H.; Lee, M.; Lee, S.; Yoo, H.; Chang, J.H.; Kim, H. Microbubbles used for contrast enhanced ultrasound and theragnosis: A review of principles to applications. Biomed. Eng. Lett. 2017, 7, 59-69. [CrossRef]

18. De Leon, A.; Perera, R.; Hernandez, C.; Cooley, M.; Jung, O.; Jeganathan, S.; Abenojar, E.; Fishbein, G.; Sojahrood, A.J.; Emerson, C.C.; et al. Contrast enhanced ultrasound imaging by nature-inspired ultrastable echogenic nanobubbles. Nanoscale 2019, 11, 15647-15658. [CrossRef]

19. Brady-Kalnay, S.M.; Tonks, N.K. Identification of the homophilic binding site of the receptor protein tyrosine phosphatase PTP mu. J. Biol. Chem. 1994, 269, 28472-28477. [CrossRef]

20. Aricescu, A.R.; Hon, W.C.; Siebold, C.; Lu, W.; van der Merwe, P.A.; Jones, E.Y. Molecular analysis of receptor protein tyrosine phosphatase mu-mediated cell adhesion. EMBO J. 2006, 25, 701-712. [CrossRef] [PubMed]

21. Cismasiu, V.B.; Denes, S.A.; Reilander, H.; Michel, H.; Szedlacsek, S.E. The MAM (meprin/A5-protein/PTPmu) domain is a homophilic binding site promoting the lateral dimerization of receptor-like protein-tyrosine phosphatase mu. J. Biol. Chem. 2004, 279, 26922-26931. [CrossRef] 
22. Martin, C.E.; List, K. Cell surface-anchored serine proteases in cancer progression and metastasis. Cancer Metastasis Rev. 2019, 38, 357-387. [CrossRef]

23. Braun, E.; Sauter, D. Furin-mediated protein processing in infectious diseases and cancer. Clin. Transl. Immunol. 2019, 8, e1073. [CrossRef]

24. Mitschke, J.; Burk, U.C.; Reinheckel, T. The role of proteases in epithelial-to-mesenchymal cell transitions in cancer. Cancer Metastasis Rev. 2019, 38, 431-444. [CrossRef] [PubMed]

25. Burden-Gulley, S.M.; Gates, T.J.; Burgoyne, A.M.; Cutter, J.L.; Lodowski, D.T.; Robinson, S.; Sloan, A.E.; Miller, R.H.; Basilion, J.P.; Brady-Kalnay, S.M. A novel molecular diagnostic of glioblastomas: Detection of an extracellular fragment of protein tyrosine phosphatase mu. Neoplasia 2010, 12, 305-316. [CrossRef]

26. Burgoyne, A.M.; Palomo, J.M.; Phillips-Mason, P.J.; Burden-Gulley, S.M.; Major, D.L.; Zaremba, A.; Robinson, S.; Sloan, A.E.; Vogelbaum, M.A.; Miller, R.H.; et al. PTPmu suppresses glioma cell migration and dispersal. Neuro Oncol. 2009, 11, 767-778. [CrossRef]

27. Burgoyne, A.M.; Phillips-Mason, P.J.; Burden-Gulley, S.M.; Robinson, S.; Sloan, A.E.; Miller, R.H.; Brady-Kalnay, S.M. Proteolytic cleavage of protein tyrosine phosphatase mu regulates glioblastoma cell migration. Cancer Res. 2009, 69, 6960-6968. [CrossRef]

28. Johansen, M.L.; Vincent, J.; Gittleman, H.; Craig, S.E.L.; Couce, M.; Sloan, A.E.; Barnholtz-Sloan, J.S.; Brady-Kalnay, S.M. A PTPmu Biomarker is Associated with Increased Survival in Gliomas. Int. J. Mol. Sci. 2019, 20, 2372. [CrossRef]

29. Burden-Gulley, S.M.; Qutaish, M.Q.; Sullivant, K.E.; Lu, H.; Wang, J.; Craig, S.E.; Basilion, J.P.; Wilson, D.L.; Brady-Kalnay, S.M. Novel Cryo-Imaging of the Glioma Tumor Microenvironment Reveals Migration and Dispersal Pathways in Vivid ThreeDimensional Detail. Cancer Res. 2011, 71, 5932-5940. [CrossRef] [PubMed]

30. Burden-Gulley, S.M.; Qutaish, M.Q.; Sullivant, K.E.; Tan, M.; Craig, S.E.; Basilion, J.P.; Lu, Z.-R.; Wilson, D.L.; Brady-Kalnay, S.M. Single cell molecular recognition of migrating and invading tumor cells using a targeted fluorescent probe to receptor PTPmu. Int. J. Cancer 2012, 132, 1624-1632. [CrossRef]

31. Mazzetti, S.; Frigerio, S.; Gelati, M.; Salmaggi, A.; Vitellaro-Zuccarello, L. Lycopersicon esculentum lectin: An effective and versatile endothelial marker of normal and tumoral blood vessels in the central nervous system. Eur. J. Histochem. 2004, 48, 423-428. [CrossRef]

32. Gearing, A.J.; Hemingway, I.; Pigott, R.; Hughes, J.; Rees, A.J.; Cashman, S.J. Soluble forms of vascular adhesion molecules, E-selectin, ICAM-1, and VCAM-1: Pathological significance. Ann. N. Y. Acad. Sci. 1992, 667, 324-331. [CrossRef]

33. Banks, R.E.; Gearing, A.J.; Hemingway, I.K.; Norfolk, D.R.; Perren, T.J.; Selby, P.J. Circulating intercellular adhesion molecule1 (ICAM-1), E-selectin and vascular cell adhesion molecule-1 (VCAM-1) in human malignancies. Br. J. Cancer 1993, 68, 122-124. [CrossRef]

34. Velikova, G.; Banks, R.E.; Gearing, A.J.H.; Hemingway, I.; Forbes, M.A.; Preston, S.R.; Jones, M.J.K.; Wyatt, J.E.; Miller, K.D.; Ward, U.; et al. Circulating soluble adhesion molecules E-cadherin, E-selectin, intercellular adhesion molecule-1 (ICAM-1) and vascular cell adhesion molecule-1 (VCAM-1) in patients with gastric cancer. Br. J. Cancer 1997, 76, 1398-1404. [CrossRef] [PubMed]

35. Katayama, M.; Hirai, S.; Kamihagi, K.; Nakagawa, K.; Yasumoto, M.; Kato, I. Soluble E-cadherin fragments increased in circulation of cancer patients. Br. J. Cancer 1994, 69, 580-585. [CrossRef] [PubMed]

36. De Wever, O.; DeRycke, L.; Hendrix, A.; De Meerleer, G.; Godeau, F.; Depypere, H.; Bracke, M. Soluble cadherins as cancer biomarkers. Clin. Exp. Metastasis 2007, 24, 685-697. [CrossRef] [PubMed]

37. Bianchi, C.; Sellke, F.W.; Del Vecchio, R.L.; Tonks, N.K.; Neel, B.G. Receptor-type protein-tyrosine phosphatase mu is expressed in specific vascular endothelial beds in vivo. Exp. Cell Res. 1999, 248, 329-338. [CrossRef]

38. Sui, X.F.; Kiser, T.D.; Hyun, S.W.; Angelini, D.J.; Del Vecchio, R.L.; Young, B.A.; Hasday, J.D.; Romer, L.H.; Passaniti, A.; Tonks, N.K.; et al. Receptor protein tyrosine phosphatase micro regulates the paracellular pathway in human lung microvascular endothelia. Am. J. Pathol. 2005, 166, 1247-1258. [CrossRef]

39. Koop, E.A.; Lopes, S.M.C.D.S.; Feiken, E.; Bluyssen, H.A.R.; Van Der Valk, M.; Voest, E.E.; Mummery, C.L.; Moolenaar, W.H.; Gebbink, M.F.B.G. Receptor protein tyrosine phosphatase mu expression as a marker for endothelial cell heterogeneity; analysis of RPTPmu gene expression using LacZ knock-in mice. Int. J. Dev. Biol. 2003, 47, 345-354.

40. Young, B.A.; Sui, X.; Kiser, T.D.; Hyun, S.W.; Wang, P.; Sakarya, S.; Angelini, D.J.; Schaphorst, K.L.; Hasday, J.D.; Cross, A.S.; et al. Protein tyrosine phosphatase activity regulates endothelial cell-cell interactions, the paracellular pathway, and capillary tube stability. Am. J. Physiol. Cell. Mol. Physiol. 2003, 285, L63-L75. [CrossRef]

41. Shetty, M. Imaging and Differential Diagnosis of Ovarian Cancer. Semin. Ultrasound CT MRI 2019, 40, 302-318. [CrossRef]

42. Vincent, J.; Craig, S.; Johansen, M.; Narla, J.; Avril, S.; DiFeo, A.; Brady-Kalnay, S. Detection of Tumor-Specific PTPmu in Gynecological Cancer and Patient Derived Xenografts. Diagnostics 2021, 11, 181. [CrossRef]

43. Johansen, M.L.; Gao, Y.; Hutnick, M.A.; Craig, S.E.L.; Pokorski, J.K.; Flask, C.A.; Brady-Kalnay, S.M. Quantitative Molecular Imaging with a Single Gd-Based Contrast Agent Reveals Specific Tumor Binding and Retention in Vivo. Anal. Chem. 2017, 89, 5932-5939. [CrossRef] [PubMed]

44. Hernandez, C.; Abenojar, E.C.; Hadley, J.; De Leon, A.C.; Coyne, R.; Perera, R.; Gopalakrishnan, R.; Basilion, J.P.; Kolios, M.C.; Exner, A.A. Sink or float? Characterization of shell-stabilized bulk nanobubbles using a resonant mass measurement technique. Nanoscale 2019, 11, 851-855. [CrossRef] [PubMed] 
45. Wu, H.; Abenojar, E.C.; Perera, R.; De Leon, A.C.; An, T.; Exner, A.A. Time-intensity-curve Analysis and Tumor Extravasation of Nanobubble Ultrasound Contrast Agents. Ultrasound Med. Biol. 2019, 45, 2502-2514. [CrossRef] [PubMed]

46. Quaia, E.; Sozzi, M.; Angileri, R.; Gennari, A.G.; Cova, M.A. Time-Intensity Curves Obtained after Microbubble Injection Can Be Used to Differentiate Responders from Nonresponders among Patients with Clinically Active Crohn Disease after 6 Weeks of Pharmacologic Treatment. Radiology 2016, 281, 606-616. [CrossRef] 